\title{
How Do Non-Clinical Paranoid and Socially Anxious Individuals React to Failure? The Role of Hostility and State Anxiety
}

\author{
Barbara Lopes $^{1 *}$ and Jose Augusto Veiga Pinto-Gouveia ${ }^{2}$
}

${ }^{1}$ Southampton Solent University, East Park Terrace, Southampton, Hamsphire, SO14 OYN, United Kingdom

${ }^{2}$ Faculdade de Psicologia e de Ciencias de Educacao da Universidade de Coimbra Rua do Colegio Novo, Apartado 6153, P- 3001- 802, Coimbra, Portugal

\begin{abstract}
Background: Theoretical models of persecutory delusions have emphasized the impact of negative emotion namely anxiety at the early stages of symptom formation. Also, studies on persecutory delusions have discovered that trait anger is associated to the presence of paranoid delusions.

Method: We did a quasi experimental study that induced social stress. Firstly we constituted three groups based on standardized cut off scores for measures of paranoia, social anxiety and depression: a paranoia group vs. a socially anxious group vs. a control group. We then measured the psychological characteristics of the three groups by self-report at time 1 (before the experiment). Participants were randomly assigned to the conditions of success vs. failure of personal performance in a computer game task. After the experience (time 2) participant's positive vs. negative emotional reactions to performance and their levels of multidimensional paranoid ideation, anger and anxiety were measured by self-report.
\end{abstract}

Results: A MANCOVA revealed a statistically significant interaction between group $\mathrm{x}$ condition for the emotional reactions to performance but not for the paranoid ideation at time 2. Results further revealed that hostility acted as a vulnerability factor, presenting a main statistically significant effect on paranoid reactions (time 2) and interacted with the independent variables of group belonging and experimental condition for an increase on the frequency of paranoid ideation, whereas anxiety interacted with group and condition for an increase of the distress of paranoid ideation.

Conclusions: The importance of temperamental hostility and anxiety suggest clinical interventions that would help individuals to deal with their anger and anxiety preventing the development and maintenance of paranoid ideation.

\section{Practitioner Points:}

- Managing feelings of resentment in clinical practice to prevent paranoid ideation.

- Addressing feelings of anxiety and managing anger to prevent paranoid ideation with the help of compassionate mind training and relaxation.

\section{Introduction}

Theoretical models for persecutory delusions such as the threat anticipation model has been proposing that paranoid delusions are the result of an interaction between vulnerability factors (such as traits of paranoia), emotional processes (anxiety) and reasoning biases [1]. According to this model, state anxiety will be misinterpreted by the individual as evidence of objective threat. The few experimental studies conducted so far support the notion that anxiety could play a role in the formation of persecutory delusions rather than merely arising as a consequence of symptoms [2]. Indeed, a study by Lincoln et al. [3] found an increase in paranoia to arise from a noise stressor in a healthy sample of individuals. The increase in paranoia was particularly high for those with high baseline paranoia. Also, state anxiety was associated to an increase of paranoid beliefs following the presentation of a stressor. Lincoln et al. [3] thus argued that state anxiety feelings may lead to paranoid beliefs hence giving support to Freeman and Garety's argument that anxiety is the link between neurosis and psychosis. Furthermore, there are studies that appear to suggest that paranoia is associated to both negative emotion and an aggressive temperament (Campbell and Morrison, 2007).

Under the light of evolutionary theory, Allan and Gilbert [4] have found that a heightened angry reaction to criticism and perceived affronts or negative evaluations could be viewed as the tendency to react angrily to an actual or potential downgrading or the loss of social standing. The trigger for this form of anger has also been related to shame and humiliation [5]. Individuals sensitive to social criticism may be especially susceptible to their perceived social standing and perceived image (Leary, 1983) that is they are "rank sensitive". Thus, it is generally assumed that individuals that yield negative views about others (i.e. perceive them as malevolent, untrustworthy, dangerous) and perceive themselves as being above rank (i.e. superior) to others tend to express anger (to be verbally and physically aggressive), while individuals that yield mainly negative self-views (see themselves as useless, unlovable, unwanted) perceive themselves as being below rank (i.e.) and inferior to others may ruminate on angry thoughts but do not express anger, instead they appear to fear social situations, which then leads them to show submissive behaviors, such as the avoidance

*Corresponding author: Barbara Lopes, Southampton Solent University, East Park Terrace, Southampton, Hamsphire, SO14 OYN, United Kingdom, Tel: +44(0)23 8031 9030; E-mail: barbaracslopes@gmail.com

Received January 22, 2012; Accepted February 28, 2012; Published March 01, 2012

Citation: Lopes B, Pinto-Gouveia JAV (2012) How Do Non-Clinical Paranoid and Socially Anxious Individuals React to Failure? The Role of Hostility and State Anxiety. J Forensic Res 3:144. doi:10.4172/2157-7145.1000144

Copyright: ( 2012 Lopes B, et al. This is an open-access article distributed unde the terms of the Creative Commons Attribution License, which permits unrestricted use, distribution, and reproduction in any medium, provided the original author and source are credited. 
of confrontation and of general social settings (Gilbert \& Miles, 2000). Indeed, the main rationale of social anxiety argues that individuals that present social anxiety and or depressive symptoms coupled with low self esteem may blame themselves for criticism and rejections, especially if they see such aversive social outcomes as due to their own inadequacy or inferiority [6]. Socially anxious individuals thus attempt to please others (perceived as possessing more positive qualities and talent than oneself) by showing themselves as non-threatening, submissive and compliant, therefore repressing feelings of anger [7]. In contrast to this, authors have been arguing that individuals that present vulnerability factors such as paranoid traits and both low levels of depressive symptomatology and normal explicit self-esteem (poor me paranoia) [8] not only show the belief that the malevolence of others is unjustified but also display a tendency to be overly aggressive $[9,10]$. Indeed, under an evolutionary view, authors such as Gilbert $[9,10]$ have been arguing that the paranoid perceptions of others as malevolent and injustified may lead to aggressive attitudes that in turn help to maintain the belief that others intend to harm oneself. This will therefore lead to a vicious cycle of self's negative views of others.

There are studies that suggest that anger is related to sub-clinical paranoid ideation [11] and that hostility is associated to paranoia in non-clinical samples [12]. However, the importance of aggressive traits hasn't been fully understood and studied in non-clinical paranoid samples, particularly the importance of a relationship between an aggressive temperament and the experience of stressful experiences, such as failing in a task and being subjected to the evaluation of personal talents and the presence of concomitant interpersonal sensitivities, such as external shame (shame of what other people think of us) as predictors of paranoid ideation.

This being the case, this study set out to examine non-clinical paranoid vs. socially anxious individuals' emotional and paranoid reactions to stress by using a vulnerability $\mathrm{x}$ stress experimental model. This model has been extensively researched in the context of depression (e.g. investigated a causal relationship for the establishment of depressogenic symptoms or moods that included the attributional diathesis (internal locus) $\mathrm{x}$ failure (external locus) interaction; see Metalski, Joiner, Hardin, \& Abramson's, 1993 reformulated model of hopelessness and the mediating effect of self-esteem). Although there are advantages to this method, it is difficult to interpret the causal direction between stress and symptoms due to the complex interactions between the individual and his/her environment in day-to-day life [3]. However in spite of this model's shortcomings and to our knowledge of the literature, there aren't many studies that compare non-clinical paranoid versus socially anxious individuals's paranoid and emotional reactions to failure, which therefore shows the importance of studying not only situations of environmental stress but in particular social stress and also situations of negative social evaluation and loss of rank and their relationship to paranoia.

Hence, the main aim of the study was to explore the impact of a stressful condition of induced failure on individuals that show paranoid ideation versus individuals that show social anxiety and controls. The study thus presented the following hypotheses:

a) The vulnerability $x$ stress model of an interaction between Group $\mathrm{x}$ Condition should significantly predict emotional reactions to performance success vs. failure but not the paranoid ideation at time 2 .

b) The Paranoid Group should show significantly more negative reactions to the experimental conditions, such as significantly more anger, depressive psychopathology, external shame, paranoid ideation and state social paranoia than the Socially Anxious Group that in turn, should show positive views of others's behaviours towards them and significantly more anger control and anxiety feelings than the Paranoia Group.

c) Hostility should act as a vulnerability factor for the frequency of paranoid thoughts whereas state anxiety and symptoms of anxiety should act as a vulnerability factor for the distress of paranoid thoughts.

\section{Method}

We devised two experimental groups and one control group from a pool of 223 college students, by applying researchers' standardized norms in the literature for cut off scores on measures of paranoia and social anxiety (see Combs et al. [12], for cut off scores in General Paranoia Scale - GPS; Fenigstein and Vanable [13]; and see PintoGouveia et al. (2003) [14] for cut off scores on the Social Interaction and Performance Anxiety Avoidance Scale- SIPAAS and on the Fear of Negative Evaluations Scale -FNE; Pinto-Gouveia, et al. (1986) [15]; Watson and Friend [16]). We point out that all the instruments used in this study were translated into Portuguese by a bilingual translator and the compatibility of content was verified through stringent backtranslation procedures.

\section{Experimental and control groups}

Paranoia group (PG): This group consisted of 28 participants who were selected according to the following rule of a cut of score plus a standard deviation in the General Paranoia Scale (GPS $\geq 53$; + $1 \mathrm{SD}$ ), a commonly used measure of subclinical paranoid ideation $[12,13]$. Also all individuals had to show clear paranoid beliefs in the PEPS that measures the acknowledgement of personal experiences of paranoia and key cognitive, behavioural and affective dimensions of paranoia $[17,18]$. Those who weren't eliminated from this group, The PG thus presented the highest levels of trait paranoia, presenting a $\mathrm{M}=57.30, \mathrm{SD}=8.932$ on the GPS. Depressive symptomatology was controlled by the scores of the DASS- 42 . This questionnaire measured current symptoms of depression, anxiety and stress and is consistently used in the literature to measure emotional stress [19] in non-clinical populations. This group presented the following means of depressive symptomatology: DASS- 42 "Depression" ( $\mathrm{M}=9.00, \mathrm{SD}=8.520)$; "Anxiety" ( $\mathrm{M}=6.57, \mathrm{SD}=4.228)$ and "Stress" $\mathrm{M}=15.03 ; \mathrm{SD}=6.161)$ Although those values are slightly higher than the scores obtained in a large Portuguese sample by Pais-Ribeiro et al. [19], this group did not show symptoms of clinical depression and anxiety. From the 28 participants, 22 were women $(78.6 \%)$ and 6 were men $(21.4 \%)$. The mean age for this group was $\mathrm{M}=20.32 ; \mathrm{SD}=4.869$ and the mean for the number of years at school was $\mathrm{M}=13.21, \mathrm{SD}=1.792$, which is equivalent to a secondary school diploma and presently attending the first year of college education. Females statistically significantly differed from males on the distress of paranoid thoughts of the PC $(\mathrm{t}(26)=-2.429, \mathrm{p}=.020)$ and on the anxiety scores of the DASS-42 ( $\mathrm{t}(26)=-2.725, \mathrm{p}=.018)$. We found similarly to Freeman et al. [20] that females reported higher distress of paranoid thoughts and more anxiety than males.

Social anxiety group (SAG): This group consisted of 28 participants that were selected according to the following cut-off scores on the "distress/anxiety subscale" of the SIPAAS (SIPAAS "Distress/Anxiety" $>115$ ) and on the "avoidance subscale" of the SIPAAS (SIPAAS "Avoidance" >105), and > 110 on the Fear of Negative Evaluation Scale 
(FNE). The SIPAAS is a commonly used measure of social anxiety and those cut-off scores for each of the subscales allow a reliable distinction between generalized social phobics from a non-clinical population [14]. This group thus showed the highest levels of social anxiety's behaviours and of the fear of negative evaluations $(M=122.90, S D=7.921$ for the SIPAAS's total anxiety score and $M=106.25, S D=3.304$ for the SIPAAS's total avoidance score and $\mathrm{M}=109.04, \mathrm{SD}=18.627$ for the total score of the fear of negative evaluation) coupled with medium to low trait paranoia $(M=39.50, S D=9.609)$. Depression and anxiety symptoms were controlled for and the scores for each of the DASS-42 dimensions were: "Depression" ( $\mathrm{M}=7.25, \quad \mathrm{SD}=5.023)$; "Anxiety " $(\mathrm{M}=6.54$; $\mathrm{SD}=4.615)$ and "Stress" $(\mathrm{M}=11.91 ; \mathrm{SD}=5.741)$. These scores were very similar to those obtained by Pais-Ribeiro et al. [19] and this meant that this group did not show symptoms of clinical depression or general anxiety. As it was expected due to its social phobic characteristics the score on anxiety was slightly higher in this group than in Pais-Ribeiro et al.'s sample. The Social Anxiety Group was also mainly comprised of females $n=22$ and only 6 males. Females statistically significantly differed from males concerning age $(\mathrm{t}(26)=-4.161, \mathrm{p}<0.001)$ and years of education ( $\mathrm{t}(26)=-3.161, \mathrm{p}=.005)$. Females were both older and presented a higher educational level than males.

Control group (CG): This group was composed by 28 participants selected accordingly the following cut off scores GPS $<30$; SIPAASanxiety and avoidance $<70$; FNE $<80$; DASS-42 depression, anxiety and stress $<10$. The Mean age for this group was of $\mathrm{M}=19.75 \mathrm{SD}=3.732$ and the mean of years spent at school was of $\mathrm{M}=12.37, \mathrm{SD}=.8242$. This meant that this group was slightly older than the ones before but was also presently attending the first year of college studies. This group presented very low scores on paranoia as measured by GPS $(\mathrm{M}=23.2, \mathrm{SD}=.834)$; on social anxiety behaviors as measured by SIPAAS "Anxiety" $(\mathrm{M}=$ $55.1, \mathrm{SD}=5.463)$ SIPAAS "Avoidance" $(\mathrm{M}=55.5, \mathrm{SD}=5.784)$ and $\mathrm{FNE}$ $(\mathrm{M}=75.1, \mathrm{SD}=7.654)$ and no symptoms of psychopatology: DASS- 42 "Depression" ( $\mathrm{M}=1.95, \mathrm{SD}=1.835)$; "Anxiety" $(\mathrm{M}=2.83, \mathrm{SD}=3.447)$ and "Stress" ( $M=6.33, S D=5.539)$. There were no participants in this group that acknowledged having paranoid beliefs on the PEPS. This group like the ones before was composed mainly of females $n=21$ than males $n=7$. The only statistically significant difference between females and males was on the years of education $\mathrm{t}(26)=-2.257, \mathrm{p}=.035$ ) Females presented a slightly higher level of education than males. None of the participants of the three groups was presently being medicated for a mental disorder and attending therapy (Table 1).

Group differences: There were no statistically significant differences between the three groups on age $\mathrm{F}(2,75)=1.578, \mathrm{p}=.213$ and on the female: male ratio $\chi^{2}(\mathrm{df}=1,76=.421, \mathrm{p}=.810)$. There were

\begin{tabular}{|l|c|c|c|c|c|c|}
\hline Variables & \multicolumn{2}{|c|}{$\begin{array}{c}\text { Paranoia Group } \\
\text { (PG) }\end{array}$} & $\begin{array}{c}\text { Social Anxiety } \\
\text { Group (SAG) } \\
\text { M SD }\end{array}$ & \multicolumn{2}{c|}{$\begin{array}{c}\text { Control Group } \\
\text { (CG) } \\
\text { M SD }\end{array}$} \\
\hline Age & 20.32 & 4.869 & 18.54 & .658 & 19.75 & 3.732 \\
\hline School years & 13.21 & 1.278 & 12.29 & .464 & 12.37 & 8.242 \\
\hline GPS_total & 57.30 & 8.932 & 39.50 & 9.609 & 23.20 & .834 \\
\hline SIPAAS_Anxiety & 103.269 & 23.242 & 122.90 & 7.921 & 55.15 & 5.463 \\
\hline SIPAAS_Avoidance & 92.55 & 21.258 & 106.25 & 3.304 & 55.50 & 5.784 \\
\hline FNE_total & 99.71 & 16.351 & 109.04 & 18.627 & 75.11 & 7.654 \\
\hline DASS_depression & 9.00 & 8.520 & 7.25 & 5.023 & 1.95 & 1.835 \\
\hline DASS_anxiety & 6.57 & 4.220 & 6.54 & 4.615 & 2.83 & 3.477 \\
\hline DASS_stress & 15.03 & 6.161 & 11.91 & 5.741 & 6.33 & 5.539 \\
\hline
\end{tabular}

Table 1: Groups's characteristics and Means and SDs for age, school years, trait paranoia, social anxiety's behaviours and depressive symptomatology. more females than males in both three groups. There were statistically significant differences between the groups though concerning the years spent at school $\mathrm{F}(2,75)=4.619, \mathrm{p}<.015$. A Post-Hoc Tukey test showed that the PG significantly differed from the SAG $(\mathrm{t}=.9226, \mathrm{p}<.030)$. The PG presented a higher level of education than the SAG. This means that the PG spent more years at school than the SAG.

Before the experimental sessions took place (time 1), participants were required to fill in a battery of questionnaires that would be required to be filled yet again after playing the game and receiving feedback during the experimental sessions (i.e. time 2).

Instruments : (i) Depression and anxiety stress scale (DASS-42) [19,21]: This questionnaire measures the affective states of depression, anxiety and stress. 42 items correspond to a phrase that presented negative emotional symptoms. The minimum score for each subscale (depression, anxiety and stress) is 0 and the maximum score is 42. Higher scores indicate higher levels of emotional distress. The Portuguese version of this scale [19] showed good psychometric properties with a Cronbach alpha of 0.96 for depression $(0.91$ in the original version); 0.90 for anxiety ( 0.81 in the original version) and 0.93 for stress (0.90 in the original version).

(ii) Paranoia checklist (PC) [17,20]: The PC is an 18-item selfreport multidimensional scale developed to measure paranoid ideation. Items are each rated on 5-point Likert scales for frequency, degree of conviction, and distress and has excellent internal consistency (Cronbach's $\alpha>0.90$ ) and good convergent validity. This study presented the following Cronbach's alphas: 0.89 (frequency), 0.95 (conviction) and 0.95 (distress).

(iii) State-trait anxiety inventory (STAI) [22,23]: State anxiety is measured by 20 items that evaluate current level of anxiety (e.g. "I feel nervous"). Each item is rated on a 4 point scale ( $1=$ Not at all, $5=$ Very much so). Higher scores indicate higher levels of anxiety. Trait anxiety was measured using the Trait anxiety subscale (20 items) of this inventory. STAI scores range from 20 (almost never anxious) to 80 (almost always anxious). This questionnaire is widely used in the literature to control for anxiety induced by the experimental situation and a general tendency to be anxious [2].

(iv) Other as shamer scale (OAS) [24,25]: The OAS is an 18 items scale that asks respondents to indicate the frequency of their feelings and experiences to items such as "I feel insecure about others opinions of me" and "Other people see me as small and insignificant" on a 5 -point Likert scale $(0-4)$. This scale offers a measure of beliefs of "being looked down on" (seen as low-rank) shame or stigmatizing shame. Higher scores indicate high levels of shame about how others view oneself (i.e. external shame). This scale has shown satisfactory internal consistency [24]. The Cronbach's alpha for this scale was of .94 in this study.

(v) The state- trait anger expression inventory (STAXI) [23,26]: The STAXI [26] is a 44-item inventory which measures the experience and expression of anger in a 4 point response scale. Higher scores correspond to high levels of anger. State Anger corresponds to current subjective feelings of anger that vary from irritability to intense rage. The chronic trait anger refers to a tendency to perceive situations as annoying and irritating. The "Trait Anger (total)" measure is composed of two sub-scales. First, anger resulting from temperament and requiring no provocation, called "Trait Anger (Temperament)". Second, the disposition to express anger when criticised or treated unfairly, here called "Trait Anger (react to criticism)". There are 
three anger expression scales (AX) to assess how respondents behave when angry or furious. "Anger in" measures the frequency of anger suppression (8 items e.g. "sulk"), "Anger out" measures the frequency of anger expression (8 items e.g. "say nasty things"), and "Anger control" measures the frequency of attempts to control the experience of anger (8 items e.g. "I control my temper"). The "Total Anger Expressed" measures the frequency of anger expression regardless of direction. The literature reported good psychometric characteristics for this questionnaire and subscales [26]. We obtained the following Cronbach alphas of .94 for "State Anger", .90 for "Trait anger" and .64 for" Anger In" and - .85 for "Anger out" respectively.

(vi) Aggression questionnaire (AQ) [25,27]: This scale tackles several components of an aggressive temperament. Participants have to rate in a 5 point Likert scale how much each statement reflects their character and behaviour ( $1=$ not at all to $5=$ very much). The scale is composed of four subscales: Physical Aggression, Verbal Aggression, Anger and Hostility. Higher scores indicate more anger (experiences of anger such as flaring up), hostility (resentment) and aggressive behaviours (such as hitting and shouting). These factors have good internal consistency and stability over time. In our study the Cronbach's alphas for each dimension were the following: 0.84 (physical aggression); 0.69 (verbal aggression); 0.80 (anger) and 0.81 (hostility).

(vii) State social paranoia scale (SSPS) $[25,28]$ : The SSPS is a 20item self-report questionnaire devised to measure the occurrence of persecutory thoughts about virtual reality characters. For the purpose of this study we use the SSPS as a measure of "state social paranoia", that is the occurrence of persecutory thoughts about "real" people, the researcher and other students present in the experimental setting. This questionnaire has three subscales: "Persecution" that presents 10 items assessing paranoid thinking (e.g. "Someone had it in for me") that fulfill the criteria of an established definition of persecutory ideation; "Neutral" that measures neutral ideation about people in experimental setting (e.g. "I wasn't really noticed by anybody") and "Positive" that measures positive ideation about the people present in the experimental setting (e.g. "Someone was friendly towards me"). Each of the 20 items is rated on a 5 -point-scale ( $1=$ Do not agree, $5=$ Totally agree). Higher scores indicate higher endorsement. The original version of the scale showed good internal good internal reliability $(\alpha=0.90)$ and clear convergent validity (Freeman et al., 2007) [28]. In our study the scale showed moderate internal reliability $(\alpha=0.60)$.

\section{Experimental Design}

The study is quasi-experimental and intended to induce social stress by evaluating participants and giving feedback on their personal skills. We used the vulnerability x stress model but we modified it. Hence, we defined groups according to psychological characteristics (paranoia vs. social phobia vs. control group) that we expected would act as a vulnerability factor for psychopathology (anxiety, paranoid ideation), emotional reactions (negative) and aggressive behaviour. Participants from the three groups were randomly assigned to two experimental conditions: Success $(n=14)$ vs. Failure $(n=14)$ and then seated in front of separate computers. Participants were informed that they would play a computer game that tested their reasoning, visual-spatial and concentration abilities. The game is composed of cards with different geometric features (SET GAME: http://www.setgame.com).

The experimenters followed a clear protocol to rule out administration biases. Participants were shown a visual presentation of the computer game. Then they were warned that they would be evaluated by the researcher on their performance abilities in this particular game. Before going to the practice session, participants were asked to fill in vignettes that assessed their feelings of anxiety and paranoia in loco in a 7 point response scale from $1=$ not at all to $7=$ very much). They were also required to fill in the first part of a questionnaire of self-perceptions (5 positive adjectives e.g." I am intelligent" versus 5 negative adjectives "I am unintelligent") [29].

The researcher explained orally the rules of the game and how one could compose a set. At the beginning of the practice session the researcher played a little with the participant so that they would internalize better the rule and then he/she will practice by himself/ herself. After practice, participants were asked again to answer by writing in a 7 point response scale: a) how well they expected to do in comparison to their colleagues; b) how good they consider their visual spatial abilities to be; c) how many times they play these types of computer games and d) how important is for them their performance in this game. They also had to write down their expectations about their performance by selecting from a range of $10 \%$ (top, excellent), 50\% (average) to $90 \%$ (bottom, very bad). After answering these questions, they would play the game for 15 minutes timed by the researcher.

In the Condition of Success the version of the SET GAME was the easiest (version for primary school children) and the game was set into "easy" whereas in the Condition of Failure the version of the SET GAME was advanced and the game was set into "very difficult". Also in the Condition of Failure, participants were required to play against the computer, which did not happen in the Condition of Success and therefore, this manipulation was an added stressor.

The Condition of Success did not put pressure on participants because they were informed that the goal of the game would be to find as many groups of cards that they could. On the other hand, in the Condition of Failure they would be informed that they had to achieve 14 groups and that this was to be expected because it was given the false information that this was the average performance of a college student (it was tested beforehand to be impossible to attain). Furthermore they were also faced with more features of the geometric shapes to take into account (e.g. colour and shape) during failure. This manipulation was done in order to induce failure and bad performance.

After playing the game, each one of the participants would be debriefed by the researcher about their capacities, ability to concentrate, to engage and disengage attention, about their visual-spatial capacities and overall performance. The researcher would praise their performance in the condition of success, with standardized positive feedback such as "very good at engaging and disengaging attention; the performance was very good and better than the other colleagues; well done, etc." while in the condition of failure, the researcher would give negative standardized feedback e.g. "very bad performance; difficulties in engaging and disengaging attention; extremely bad performance compared to other colleagues, etc.".

After receiving feedback, participants had to: a) fill in the visual analogue vignettes of levels of anxiety and presence of paranoid feelings in loco at time 2; b) describe their perceived performance (how well they did compared to what they expected before playing the game and compared to other college students in a scale of $10 \%$ - top excellent to $90 \%$ - very bad) and to write down the number the groups they obtained; c) describe their emotional reactions to the game (positive such as joy vs. negative emotions such as discontent) in a 7 point 
response scale ( $1=$ totally agree to $7=$ totally disagree) (e.g. "the game made me feel stupid") [29]; d) attribute the causes of performance (internal versus external) by answering to an anchor question in a 7 point Likert response scale ( $1=$ not at all to 7 =very much) ( "how much do you think your performance was due to external causes, such as noise?"). Finally participants were asked to fill in the time 2 post experiment battery of questionnaires that was composed by the following measures: the PC (frequency, conviction, distress); the STAI; the STAXI; the OAS, the DASS- 42 and the State Social Paranoia Scale. At the end of the experiment participants were debriefed and we made sure they understood that the feedback was not real.

\section{Data Analysis}

We performed a MANCOVA in order to examine the vulnerability $\mathrm{x}$ stress model and potential interactions on predicting the presence of paranoid ideation, anxiety, and negative emotional reactions to performance at time 2 .

Group membership (Paranoia Group- PG; Social Anxiety Group - SAG and Control Group) and Experimental condition (Success vs. Failure); temperamental hostility (AQ) anxiety symptoms (DASS-42) and state anxiety (STAI) served as the between groups' independent variables, whereas the Frequency, Conviction and Distress of Paranoid Thoughts (PC), anxiety and paranoid feelings in loco; the three dimensions of state social paranoia (SPSS-persecution, neutral and positive) and Positive and Negative Emotional Reactions to Performance at time 2 served as the dependent variables. Owing to differences between groups on years spent at school, this variable was inserted in the model as a covariate, however it didn't show a significant effect: Wilk's Lambda $=8.697, \mathrm{p}=.027, \eta_{\rho}^{2}=.062$.

Overall there was a significant multivariate effect for Group Wilk's Lambda $=1064.318, \mathrm{p}<.001, \eta^{2}=.001$, for experimental condition Wilk's Lambda $=188.976, p=<.001, \eta_{\rho}^{2}=.005$ and for Group $x$ Experimental Condition interaction Wilk's Lambda $=1457.288, \mathrm{p}<.001, \eta_{p}^{2}=.000$.

The independent variable "Group" had significant main effects on anxiety feelings at time 2(visual analogue vignettes) $(\mathrm{F}(2,84)=8.354$, $\mathrm{p}=.001)$ and on paranoid feelings at time 2 (visual analogue vignettes) (F $(2,84)=22.064, \mathrm{p}<.001)$; on positive emotional reactions to performance at time 2 (SPERQ) ( $(2,84)=22.122, \mathrm{p}=.001)$ vs. negative emotional reactions to performance at time 2(SPERQ) ( $\mathrm{F}$ $(2,84)=25.501, \mathrm{p}<.001)$; and on the three dimensions of state social paranoia (SSPS): "persecution" $(\mathrm{F}(2,84)=5.313), \mathrm{p}=.044$; "neutral" (F $(2,76)=10.989, \mathrm{p}=.008)$ and "positive" $(\mathrm{F}(2,84)=35.650, \mathrm{p}<.001)$ as well as, on the three dimensions of paranoid thoughts at time 2 : "frequency" $(\mathrm{F}(2,84)=30.649, \mathrm{p}<.001)$; "conviction" $(\mathrm{F}(2,84)=23.838, \mathrm{p}<.001)$ and "distress" $(\mathrm{F}(2,84)=7.725, \mathrm{p}=.002)$. Post Hoc Tukey HSD tests showed that the paranoid group (PG) presented on one side, significantly less feelings of anxiety in loco at time 2 than the social anxiety group (SAG) $(\mathrm{M}=3.14, \mathrm{SD}=1.556$ vs. $\mathrm{M}=4.71, \mathrm{SD}=1.822 ; \mathrm{t}=-1.3571, \mathrm{p}=.002)$. On the other hand, the PG showed significantly more paranoid feelings in loco at time than the SAG $(\mathrm{M}=3.42, \mathrm{SD}=1.730$ vs. $\mathrm{M}=1.64, \mathrm{SD}=.9114$; $\mathrm{t}=1.7381, \mathrm{p}<.001$ ). Furthermore, the paranoia group (PG) also showed significantly more state social paranoia characterized by ideas of persecution of others during the experiment, as well as significantly more paranoid ideation at time 2 (more frequency, more conviction and distress of paranoid thoughts) than the social anxiety group (SAG) (for state social paranoia -persecution: $\mathrm{M}=17.03, \mathrm{SD}=8.158$ vs. $\mathrm{M}=10.67, \mathrm{SD}=1.306 ; \mathrm{t}=6.2240, \mathrm{p}<.001$ and for the "frequency" $\mathrm{M}=43.28, \mathrm{SD}=12.988^{\text {” }}$ vs. $\mathrm{M}=25.54 \mathrm{SD}=1.643 ; \mathrm{t}=17.7440, \mathrm{p}<.001$; for the "conviction" $\mathrm{M}=48.32, \mathrm{SD}=16.101$ vs. $\mathrm{M}=30.95, \mathrm{SD}=6.054$; $\mathrm{t}=17.3631, \mathrm{p}<.001$; and finally for the "distress" of paranoid thoughts at time 2: $\mathrm{M}=37.53, \mathrm{SD}=17.961$ vs. $\mathrm{M}=24.91, \mathrm{SD}=15.122 ; \mathrm{t}=12.6910$, $\mathrm{p}=.009$ ).

As it should be expected, the paranoia group (PG) also showed significantly more paranoid feelings in loco at time 2 than the control group, which from all the three groups showed the less paranoid feelings $(\mathrm{M}=1.25, \mathrm{DP}=.5189)(\mathrm{t}=1.2798, \mathrm{p}<.001)$. Moreover, the paranoia group showed more state social paranoia-persecution and more paranoid ideation at time 2 than the control group, which showed the less state social paranoia as well as the less paranoid ideation at time 2 (for state social paranoia - persecution: $\mathrm{M}=11.25, \mathrm{SD}=1.026$; for the "frequency": $\mathrm{M}=25.54, \mathrm{SD}=4.177$; for the "conviction" $\mathrm{M}=29.33, \mathrm{SD}=6.294$ and for the "distress" of paranoid thoughts at time $2 \mathrm{M}=25.70, \mathrm{SD}=11.472$ ) $(\mathrm{t}=5.8274, \mathrm{p}<.001 ; \mathrm{t}=16.3274 . \mathrm{p}<001 ; \mathrm{t}=18.9464=\mathrm{p}<.001$ and $\mathrm{t}=13.9107$, $\mathrm{p}=.003)$. Results suggested that the paranoia group showed significantly more paranoid ideation, paranoid feelings and state social paranoia at time 2 than both the control group and the social anxiety group, which in its turn showed significantly more anxiety feelings at time 2 than the paranoia group.

Results also showed that the paranoia group presented the highest scores on "external shame" (OAS) at time $2(\mathrm{M}=30.57, \mathrm{SD}=14.713)$ followed by the social anxiety group $(\mathrm{M}=17.62, \mathrm{SD}=9.518)$ and then by the control group that presented the lowest scores $(M=16.58$, $\mathrm{DP}=7.694)$. Results showed that the paranoia group showed significantly more external shame at time 2 (i.e. shame of what other people think of them) than both the social anxiety and control groups $(\mathrm{t}=13.32143, \mathrm{p}<.001$ and $\mathrm{t}=14.21429, \mathrm{p}<.001)$.

As expected, the PG presented not only more traits of anger but also reacted with rage to the experimental conditions. Indeed, the PG showed the highest scores on trait anger $(\mathrm{M}=21.64, \mathrm{SD}=4.066)$ and on its components ("trait anger- temperament" $\mathrm{M}=6.78, \mathrm{SD}=2.514$ and "trait anger- reaction to criticism" $\mathrm{M}=11.00, \mathrm{SD}=2.434$ ). Furthermore, the PG expressed more anger at the experimental conditions. So the PG showed the highest scores on the "expression of anger" ( $M=$ $29.89, \mathrm{SD}=7.151)$ and its types of expression "anger in" (i.e. suppress) $(\mathrm{M}=18.67, \mathrm{SD}=4.260)$ vs. "anger out" (i.e. express outwardly) $(\mathrm{M}=14.82$, $\mathrm{SD}=3.801)$, except on anger "control" $(\mathrm{M}=19.60, \mathrm{SD}=4.613)$, for which the social anxiety group showed the highest scores $(M=21.75$; $\mathrm{SD}=5.471)$.

On the other hand in comparison to the PG, the social anxiety group (SAG) showed lower scores on trait anger $(\mathrm{M}=17.79, \mathrm{SD}=3.476)$ : "temperament" $(\mathrm{M}=5.08, \mathrm{SD}=1.558$ and reaction to criticism $(\mathrm{M}=9.58$, $\mathrm{DP}=2.185)$ and also, lower scores on expression of anger $(\mathrm{M}=23.08, \mathrm{SD}$ $=7.015$ : "anger in" vs. "anger out" $(\mathrm{M}=15.75, \mathrm{SD}=3.614$ vs. $\mathrm{M}=23.08$, $\mathrm{SD}=7.015)$. Results thus suggested that the paranoid group showed more traits of anger both temperamental and reactions to criticism, and also more expression of anger in both directions (in vs. out) than the social anxiety group $(\mathrm{t}=4.39286, \mathrm{p}<.001 ; \mathrm{t}=1.85714, \mathrm{p}=.001$; $\mathrm{t}=1.78572, \mathrm{p}=.003 ; \mathrm{t}=2.96429, \mathrm{p}=.006 ; \mathrm{t}=1.96429, \mathrm{p}=.021$ ). Contrary to this, results also suggested that the social anxiety group controlled much more their anger than the paranoia group after the experimental sessions ( $\mathrm{t}=-3.07143, \mathrm{p}=.005)$, which means that the paranoia group not only has a tendency to be angry and to react aggressively to criticisms but also has a problem in controlling their anger.

Moreover the paranoia group presented more depressive and anxious symptoms at time 2 than the other two groups. Indeed, the 
Citation: Lopes B, Pinto-Gouveia JAV (2012) How Do Non-Clinical Paranoid and Socially Anxious Individuals React to Failure? The Role of Hostility and State Anxiety. J Forensic Res 3:144. doi:10.4172/2157-7145.1000144

Page 6 of 9

paranoia group (PG) showed more symptoms of depression and of anxiety at time 2 than both the social anxiety group (SAG) and the control group (CG) (for the symptoms of depression: $\mathrm{M}=6.67, \mathrm{SD}=9.281$ vs. $\mathrm{M}=4.95, \mathrm{SD}=4.496$ vs. $\mathrm{M}=1.83, \mathrm{SD}=2.407$ and for the symptoms of anxiety: $\mathrm{M}=6.57, \mathrm{SD}=5.231$ vs. $\mathrm{M}=4.25, \mathrm{SD}=3.082$ vs. $\mathrm{M}=3.04, \mathrm{SD}$ $=2.196)$. Results suggested that the PG showed statistically significantly more symptoms of anxiety than the SAG $(\mathrm{t}=2.85714, \mathrm{p}=.021)$, while showing as well significantly more symptoms of depression and anxiety at time 2 than the CG $(t=4.96429, p=.008$ and $t=3.67857, p=.002)$. Thus, the paranoia group in contrast to what happened in time 1 , showed more symptoms of anxiety and depression at time 2 than both the social anxiety and the control groups. This suggested therefore that the experimental conditions induced a significant increase on depressive and anxious symptomatology in the paranoia group. Hence while initially the paranoia group did not show more vulnerability to depression and anxiety than the social anxiety group, when submitted to the experimental conditions, these induced depressive and anxious symptoms in this particular group.

As it was expected, the paranoia group (PG) presented significantly less positive emotional reactions to performance at time 2 (e.g. feelings of being pleased and valued) (SPERQ) than the control group, which from all the three groups showed the highest scores on positive emotional reactions at time $2(\mathrm{M}=15.10, \mathrm{SD}=5.667$ vs. $\mathrm{M}=19.21$, $\mathrm{SD}=3.547 ; \mathrm{t}=-4.2662, \mathrm{p}=.013$ ) (table). Similarly to the paranoia group, the social anxiety group presented significantly less positive emotional reactions to performance at time $2(\mathrm{M}=14.28, \mathrm{SD}=5.820 ; \mathrm{t}=-4.5000$, $\mathrm{p}<.001)$ than the control group. Also, the social anxiety group showed more anxiety feelings in loco than the control group that presented the less anxiety feelings $(\mathrm{M}=2.87, \mathrm{SD}=1.078 ; \mathrm{t}=1.4167, \mathrm{p}=.002)$. Furthermore, the social anxiety group presented significantly more "positive" ideation about other people's intentions and behaviours towards them at the experimental sessions (SSPS) than the paranoid group that in contrast presented more ideation of the "persecution" of others $(\mathrm{M}=18.64, \mathrm{SD}=3.851$ vs. $\mathrm{M}=15.71, \mathrm{SD}=4.250 ; \mathrm{t}=2.7857, \mathrm{p}=.021$ ). This suggested that the social anxiety group showed "positive bias" for other people's behaviours towards them during the experimental session, whereas the paranoia group showed a "persecution bias". In other words, socially anxious individuals perceive other people as friendly towards them, whereas paranoid individuals perceive others has being malevolent and having ill intentions towards them (Table 2).

The independent variable of "Condition" (Success vs. Failure) also had main effects on both anxious feelings at time 2 (visual vignettes) $\mathrm{F}$ $(1,76)=4.320, \mathrm{p}<.001$ and paranoid feelings at time 2 (visual vignettes) $\mathrm{F}(1,76)=7.566, \mathrm{p}=.008$. Nevertheless, condition only had a significant main effects for two dimensions of the SSPQ: Neutral F $(1,65)=10.134$ $\mathrm{p}<.010$ and Positive $\mathrm{F}(1,76)=64.198, \mathrm{p}<.001$.

We performed t-tests for the two dimensions of Condition (Success vs. Failure) to measure the differences between the two conditions for the several dependent variables. A t-test suggested that Success vs. Failure significantly differed on positive emotional reactions ( $t$ (74) $3.713, \mathrm{p}<.001)$ and on negative emotional reactions after performance ( $t(74)-3.664, p<.001)$. While the Success Condition seemed to induce significantly higher scores on positive emotional reactions, the Failure

\begin{tabular}{|c|c|c|c|c|c|c|}
\hline \multirow{2}{*}{$\begin{array}{l}\text { MEASURES } \\
\text { PC_Frequency }\end{array}$} & \multicolumn{2}{|c|}{$\begin{array}{c}\text { Paranoia Group } \\
\text { TIME } 2\end{array}$} & \multicolumn{2}{|c|}{$\begin{array}{c}\text { Social Anxiety Group } \\
\text { TIME } 2\end{array}$} & \multicolumn{2}{|c|}{$\begin{array}{c}\text { Control Group } \\
\text { TIME } 2\end{array}$} \\
\hline & 43.28 & 12.988 & 25.54 & 6.143 & 25.54 & 4.177 \\
\hline PC_Conviction & 48.32 & 16.101 & 30.95 & 6.0540 & 29.33 & 6.294 \\
\hline PC_Distress & 37.53 & 17.961 & 24.91 & 15.122 & 25.70 & 11.472 \\
\hline OAS_Total & 30.57 & 14.713 & 17.62 & 9.518 & 16.58 & 7.694 \\
\hline STAI_ST_ANX & 38.75 & 10.462 & 38.83 & 9.290 & 31.79 & 4.634 \\
\hline STAI_TR_ANX & 46.32 & 7.438 & 45.20 & 6.934 & 36.25 & 6.929 \\
\hline STAXI_STA & 11.78 & 4.349 & 10.41 & 1.248 & 10.20 & .41848 \\
\hline STAXI_TA & 21.64 & 4.066 & 17.79 & 3.476 & 19.50 & 1.744 \\
\hline STAXI_T_ANG_T & 6.78 & 2.514 & 5.08 & 1.558 & 5.66 & 1.090 \\
\hline STAXI_T_ANG_R & 11.00 & 2.434 & 9.58 & 2.185 & 9.37 & 1.013 \\
\hline STAXI_AX_IN & 18.67 & 4.260 & 15.75 & 3.614 & 15.70 & 2.733 \\
\hline STAXI_AX_OUT & 14.82 & 3.801 & 13.08 & 2.394 & 14.58 & 1.558 \\
\hline STAXI_AX_CON & 19.60 & 4.613 & 21.75 & 5.471 & 19.20 & 2.245 \\
\hline STAXI_AX_EX_Total & 29.89 & 7.151 & 23.08 & 7.015 & 27.08 & 3.955 \\
\hline DASS_DEP & 6.67 & 9.281 & 4.95 & 4.496 & 1.83 & 2.407 \\
\hline DASS_ANX & 6.57 & 5.231 & 4.25 & 3.082 & 3.04 & 2.196 \\
\hline DASS_STRE & 10.28 & 6.462 & 9.50 & 6.114 & 8.54 & 4.800 \\
\hline SSPS_Persecution & 17.03 & 8.158 & 10.67 & 1.306 & 11.25 & 1.506 \\
\hline SSPS_Neutral & 13.17 & 3.662 & 13.42 & 4.497 & 11.17 & 2.482 \\
\hline SSPS_Positive & 15.71 & 4.250 & 18.64 & 3.851 & 18.07 & 2.580 \\
\hline Vis_Analog_Anxiety_t2 & 3.14 & 1.556 & 4.71 & 1.822 & 2.87 & 1.078 \\
\hline Vis_Analog_Paranoia_t2 & 3.42 & 1.730 & 1.64 & .91142 & 1.25 & .51819 \\
\hline SPERQ_posit_emo_rea & 15.10 & 5.667 & 14.28 & 5.810 & 19.21 & 3.541 \\
\hline SPERQ_negative_emo_rea & 18.42 & 7.598 & 19.39 & 8. 560 & 15.46 & 6.790 \\
\hline
\end{tabular}

Vis analog anxiety t2 (total score of anxiety feelings in the visual analogue scale at time 2); Vis analog paranoia t2 (total score of paranoid feelings in the visual analogue scale at time 2) : SPERQ_posit_emo_re (total score of positive emotional reactions of the Self Perceptions and Emotional Reactions Questionnaire); SPERQ_ negative_emo_rea (total score of negative emotional reactions of the Self Perceptions and Emotional Reactions Questionnaire)

Table 2: Means and SDs for the Paranoia Group, Social Anxiety Group and Controls for the measures at time 2. 
condition seemed to induce significantly higher scores on negative emotional reactions to performance than the Success Condition. This being the case, we expected a two-way interaction between group $\mathrm{x}$ condition for positive vs. negative emotional reactions after performance (time 2). Results supported our hypothesis: $\mathrm{F}(1,65)=27.886, \mathrm{p}<.001$ and $\mathrm{F}(1,65)=26.337, \mathrm{p}<.001$ respectively.

In spite of having a significant impact on emotional reactions, the two conditions did not have a significant effect on the frequency, conviction and distress of paranoid thoughts at time 2. Also the interaction between group $\mathrm{x}$ condition was not significant for the three dimensions of paranoid thoughts at time $2(\mathrm{~F}(1,65)=15.000=.678)$. These results thus suggested that the interaction between group and condition was mediated by other variables in order to explain paranoid ideation (PC) at time 2.

The role of Temperamental Hostility as a vulnerability factor for the frequency and conviction of paranoid thoughts at time 2

Temperamental "Hostility" (AQ) had a simple statistically significant main effect on the "frequency of paranoid thoughts" (PC) $(\mathrm{F}(1,65)=5.429, \mathrm{p}=.049)$ and on the "conviction of paranoid thoughts" at time $2(\mathrm{~F}(1,65)=4.521, \mathrm{p}=.050)$, thus the higher the hostility, the more frequent and the higher conviction on paranoid thoughts $(\mathrm{r}=.733, \mathrm{p}<.001 ; \mathrm{r}=.688, \mathrm{p}<.001$ respectively). Hostility also interacted with Group $x$ condition to explain the frequency and the conviction of paranoid thoughts $(\mathrm{F}(1,65)=25.402, \mathrm{p}<.001 ; \mathrm{F}(1,65)=32.881$, $\mathrm{p}<.001$ respectively). This result suggested that hostility mediates the interaction between group and condition for both frequency and conviction of paranoid thoughts at time 2 (Figure 1).

The role of Anxiety (state) and symptoms as vulnerability factors for the distress of paranoid thoughts at time 2 .

Concerning the dimensions of negative effect, state anxiety (STAI) by itself had a simple statistically significant main effect on the distress of paranoid thoughts $(\mathrm{PC})$ at time $2(\mathrm{~F}(1,65)=13.086, \mathrm{p}=.005)$. Thus the more anxious at the experimental sessions, the more distress of paranoid thoughts $(\mathrm{r}=.232, \mathrm{p}=.042)$. State Anxiety also interacted significantly with group $\mathrm{x}$ condition to explain positive emotional reactions after performance $(\mathrm{F}(3,65)=21.607, \mathrm{p}<.001)$ and negative emotional reactions after performance $(\mathrm{F}(3,65)=19.874, \mathrm{p}<.001)$. Results suggested that anxiety feelings mediate the interaction between group $\mathrm{x}$ condition for positive vs. negative emotional reactions to performance. Furthermore, the dimension of symptoms of "anxiety" of the DASS-42 had a simple statistically significant one-way effect on the distress of paranoid thoughts at time $2(\mathrm{~F}(1,65)=13.612$, $\mathrm{p}=.004$ ). Thus the more one shows symptoms of anxiety, the higher the distress of paranoid thoughts at time $2(\mathrm{r}=.197, \mathrm{p}=.088)$. "Anxiety" (DASS-42) interacted as well with Group $\mathrm{x}$ Condition to significantly explain positive vs. negative emotional reactions after performance $(\mathrm{F}(2,65)=6136, \mathrm{p}=.008$ and $\mathrm{F}(2,65)=22.758, \mathrm{p}<.001$ respectively $)$ and paranoid feelings on the visual vignettes at time $2(\mathrm{~F}(2,73)=7.401$, $\mathrm{p}=.011$ ). This meant that symptoms of anxiety mediate the interaction between group $\mathrm{x}$ condition for the presence of paranoid feelings on visual vignettes at time 2 and of more negative emotional reactions associated to less positive emotional reactions to performance (Figure 2 and 3 )

\section{Discussion}

This study aimed to explore the psychological differences between non clinical paranoia and social anxiety and their reactions to performance (failure vs. success). We hypothesized under the light of the vulnerability $\mathrm{x}$ stress model that there should be an interaction between group $\mathrm{x}$ condition for paranoid feelings and for positive vs. negative emotional reactions to performance. Indeed, being paranoid interacts with failure to produce more negative emotional reactions to performance whereas success induced more positive emotional reactions to performance. It is important to note however, that the experimental condition was a stressor by itself independently of the feedback that was given, since the computer game was very difficult; therefore overall there weren't major differences between success vs. failure on the measures for the total sample of the two experimental groups and control group. Nevertheless, as expected, praising performance and inducing success did buffer experimental groups against negative emotional reactions and induced positive emotional reactions. Thus the experimental manipulation was successful in producing adequate emotional responses. However, it failed to have an impact by itself or interacting with group characteristics to explain the frequency, conviction and distress of paranoid thoughts at time 2 .

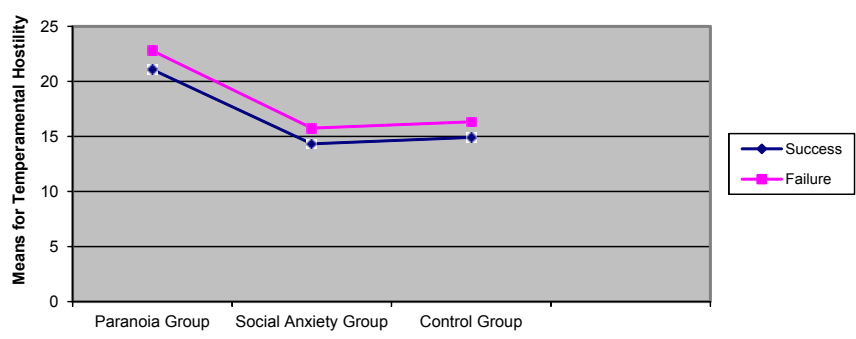

Group

Figure 1: Mean Total Scores of Temperamental Hostility for the three groups in conditions of failure vs. Success.

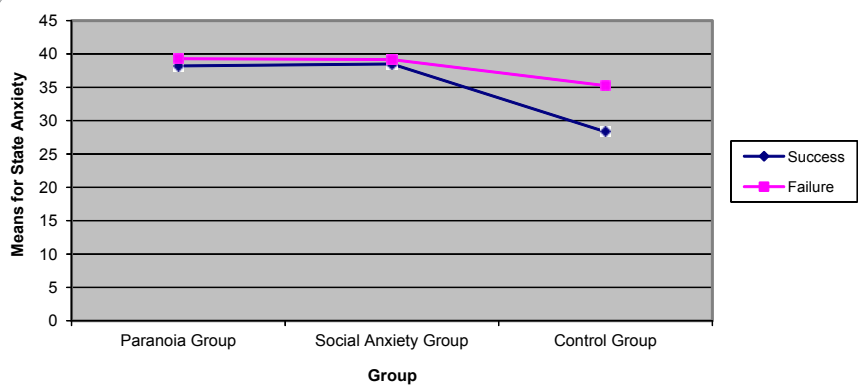

Figure 2: Mean Total Scores of State Anxiety for the three groups in conditions of failure vs. success.

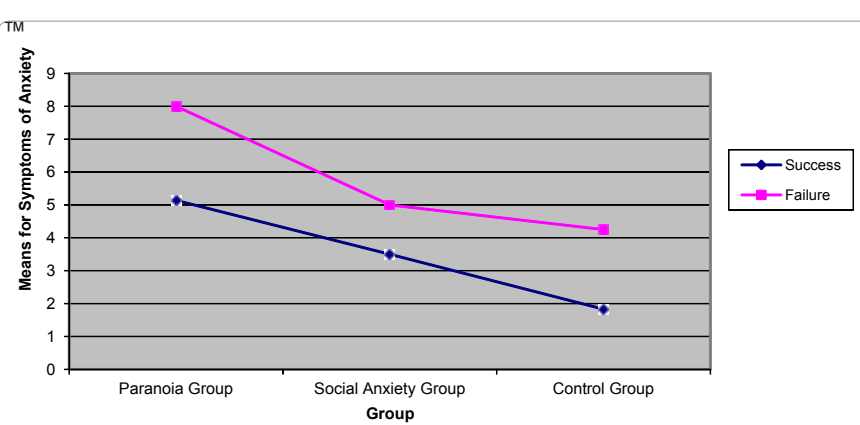

Figure 3: Mean Total Scores of Symptoms of Anxiety for the three groups in conditions of failure vs. success. 
Citation: Lopes B, Pinto-Gouveia JAV (2012) How Do Non-Clinical Paranoid and Socially Anxious Individuals React to Failure? The Role of Hostility and State Anxiety. J Forensic Res 3:144. doi:10.4172/2157-7145.1000144

Page 8 of 9

Results, as expected, demonstrated also main effects for "Group" on emotional reactions and on the presence of paranoid ideation at time 2. Since being paranoid is characterized by a range of psychological vulnerabilities such as an aggressive temperament, it is not surprising that this leads to paranoid ideation after a difficult task.

That being the case, we would expect that hostility (as a temperamental characteristic) should have a main effect on paranoid ideation on time 2 . Indeed, results showed that showing paranoid ideas and presenting hostile temperament interacted with the experimental conditions for an increase of the frequency and conviction of paranoid thoughts at time 2. This suggests that hostility has a role on the cognitive aspects of paranoia, as Combs and colleagues [12] suggested. On the other hand and in accordance to Freeman et al. $[2,30]$ anxiety symptoms and feelings have main effect on the distress of paranoid ideation at time 2 . This suggested that contrarily to hostility, anxiety (as a feeling or symptom) has an impact on the affective components of paranoia.

Also results supported the trend on literature [31] that claims that paranoia is a type of anxious fear and that both paranoia and social anxiety share underlined affective states such as anxiety, depression, worry and interpersonal sensitivities [2,30]. Indeed both our Paranoid Group and Socially Anxious group showed higher anxiety than controls and results supported the hypothesis that anxiety acts as a vulnerability factor for the distress of Paranoid thoughts of the PC while Hostility of the AQ (an attitude of resentment and coldness towards others related to interpersonal sensitivity) acted as vulnerability for the frequency and conviction of paranoid thoughts of the PC. Our study being one of the kind to our knowledge, stressed out the importance of anger to differentiate between paranoia and social anxiety [7]. Paranoia is related to trait anger and aggressive tendencies. The role of anger has not yet been fully studied in paranoia but it is extremely important. Results suggested that trait anger interacts with group to predict conviction and distress of paranoid thoughts after the experiment took place. Thus being generally aggressive is a characteristic of paranoid people and those show therefore higher paranoid conviction and distress.

There are a few limitations to the study. First the sample was constituted mainly by females. Secondly, we did not measure the influence of variables such as major life events that may have had an influence on results. Also, the computer task seemed to be stressful but we cannot infer for sure whether failing in such a task was indeed perceived as a personal stressor.

In spite of the limitations, this study also provided data that supported the feasibility of the vulnerability $\mathrm{x}$ stress model [32] for differences between paranoid individuals and socially anxious individuals on an experimental condition. Results showed a significant interaction between group $\mathrm{x}$ condition for emotional reactions to performance. Presenting non-clinical paranoia (showing traits of paranoia) differs from presenting non-clinical social anxiety in conditions of success and failure concerning paranoid and anxious feelings and persecutory ideation.

Data also suggested important clinical implications. The importance of temperamental hostility and anxiety for an increase of paranoid ideation, implies that therapeutic techniques should address feelings of resentment and anxiety in such a way individuals would be more compassionate towards their perceived flaws and the perceived malevolent characteristics' of others, preventing the development of paranoid ideation [33].

\section{References}

1. Freeman D (2007) Suspicious minds: the psychology of persecutory delusions Clin Psychol Rev 27: 425-457.

2. Freeman D, Pugh K, Antley A, Slater M, Bebbington P, et al. (2008) Virtua reality study of paranoid thinking in the general population. $\mathrm{Br} \mathrm{J}$ Psychiatry 192: $258-263$

3. Lincoln MT, Peter N, Schäfer M, Moritz S (2008) Impact of stress on paranoia: an experimental investigation of moderators and mediators. Psychol Med 39: 1129-1139.

4. Allan S, Gilbert P (1997) Submissive behaviour and psychopathology. Br J Clin Psychol 36: 467-488.

5. Gilbert P (2001) Evolution and social anxiety. The role of social attraction, social competition and social hierarchies. Psychiatr Clin North Am 24: 723-751

6. Clark \& Wells (1995) DM Clark and A Wells, A cognitive model of social phobia In: R.G. Heimberg, M. Liebowitz, DA Hope and F Schneier, Editors, Social phobia: Diagnosis, assessment and treatment, Guilford, New York.

7. Gilbert P, Boxall M, Cheung M, Irons C (2005) The relation of Paranoid Ideation and Social Anxiety in a Mixed clinical population. clin psycho psychother 12 124-133.

8. Chadwick P, Trower P (1996) Cognitive therapy for punishment paranoia: A single case experiment. Behav Res Ther 34: 351-356.

9. Gilbert P (2001) Evolutionary approaches to psychopathology: the role of natural defences. Aust N Z J Psychiatry 35: 17-27.

10. Gilbert $P$ (2001) Evolution and social anxiety: The role of attraction, socia competition and social hierarchies. In FR Schneier (Edn.) Social Anxiety Disorder: The Psychiatric Clinics of North America. Philadelphia, PA: Saunders 24: 723-751.

11. Ellett L, Lopes B, Chadwick P (2003) Paranoia in a non-clinical population of college students. J Nerv Ment Dis 191: 425-430

12. Combs RD, Penn D, Michael C, Basso M, Wiedeman R, et al. (2009) Perceptions of Hostility by persons with and without Persecutory Delusions. Cogn Neuropsychiatry 14: 30-52

13. Fenigstein A, Vanable PA (1992) Paranoia and self-consciousness. J Pers Soc Psychol 62: 129-138.

14. Pinto-Gouveia J, Cunha M, Salvador MC (2003) Assessment of Social Phobia by Self-Report Questionnaires: The Social Interaction and Performance Anxiety and Avoidance Scale and the Social Phobia Safety Behaviours Scale. Behav Cogn Psychother 31: 291-311

15. Pinto-Gouveia J, Fonseca L, Robalo M, Allen A, Matos A (1986). Ansiedade social: utilização dos questionários de auto-resposta SAD, FNE, e SISST numa população portuguesa. Psiquiatria Clínica 7: 43-48.

16. Watson D, Friend R (1969) Measurement of social-evaluative anxiety. J Consult Clin Psychol 33: 448-457.

17. Lopes B, Pinto-Gouveia J, Martins S (2009) Estudo da Adaptação Portuguesa da "General Paranoia Scale" (GPS) de Fenigstein e Vanable (1992) para duas amostras Portuguesas (estudantes e população geral). Psychologica In Press

18. Allen P, Freeman D, McGuire P, Garety P, Kuipers E (2005) The prediction of hallucinatory predisposition in non-clinical individuals: examining the contribution of emotion and reasoning. Br J Clin Psychol 44: 127-132.

19. Pais-Ribeiro J, Honrado A, Leal I (2004) Contribuição para o estudo da adaptação portuguesa das escalas de depressão ansiedade stress de Lovibond e Lovibond. Psychologica 36: 235-246

20. Freeman D, Garety PA, Bebbington PE, Smith B, Rollinson R (2005) Psychological investigation of the structure of paranoia in a non-clinical population. Br J Psychiatry186: 427-435.

21. Lovibond PF, Lovibond SH (1995). The structure of negative emotional states: comparison of the depression anxiety stress scales (DASS) with the Beck Depression and Anxiety Inventories. Behav Res Ther 33: 335-343.

22. Spielberger CD, Gorsuch RL, Lushene R, Vagg PR, Jacobs GA (1983) Manual 
Citation: Lopes B, Pinto-Gouveia JAV (2012) How Do Non-Clinical Paranoid and Socially Anxious Individuals React to Failure? The Role of Hostility and State Anxiety. J Forensic Res 3:144. doi:10.4172/2157-7145.1000144

Page 9 of 9

for the State-Trait Anxiety Inventory. Consulting Psychologists Press, Palo Alto, $\mathrm{CA}$

23. Ponciano E (2003) Adaptação das Escalas de Ansiedade Estado vs. Traço e de Raiva-Estado vs. Traço e Expressão numa população Portuguesa. Tese de Doutoramento da Universidade de Coimbra

24. Allan S, Gilbert P, Goss K (1994). An exploration of shame measures II: Psychopathology. Pers Individ Dif 17: 719-722.

25. Lopes B, Pinto -Gouveia J,Castilho P in Lopes B \& Pinto-Gouveia J (2009) A relação da paranóia com o afecto negativo em duas amostras não-clínicas da amostra Portuguesa. Psychologica In press.

26. Spielberger CD (1988): Manual for the State-Trait Anger Expression Inventory (STAXI). Psychological Assessment Resources, Odessa, FL.

27. Buss AH, Perry M (1992) The aggression questionnaire. J Pers Soc Psycho 63: 452-459.

28. Freeman D, Pugh K, Green D, Valmaggia L, Dunn G (2007) A measure of State Persecutory Ideation for experimental studies (SSPS). J Nerv Ment Dis 195: 781-784.

29. Dutton KA, Brown JD (1997) Global self-esteem and specific self-views as determinants of people's reactions to success and failure. Journal of personality an social psychology 73 : 139-148.

30. Freeman D, Gittins M, Pugh K, Antley A, Slater M, et al. (2008) What makes one person paranoid and another person anxious? The differential prediction of social anxiety and persecutory ideation in an experimental situation. Psycho Med 38: 1121-1132.

31. Freeman D, Garety PA (2003) Connecting neurosis and psychosis: The direct influence of emotion on delusions and hallucinations. Behav Res Ther 41: 923-

32. Phillips LJ, Francey SM, Edwards J, McMurray N (2007) Stress and Psychosis: towards the development of new models of investigation. Clin Psychol Rev 27: 307-317.

33. Gilbert P (2002) Evolutionary approaches to psychopathology and cognitive therapy. In P Gilbert (Edn.) Cognitive Psychotherapy: an International Quarterly (Evolutionary Psychology and Cognitive Therapy Special Edition 16: 236-264.

34. Allan S, Gilbert P (1995) A social comparison scale: Psychometric properties and relationship to psychopathology. Pers Individ Dif 19: 293-299.

35. Birley JL, Brown GW (1970) Crises and life changes preceding the onset or relapse of acute Schizophrenia: clinical aspects. Br J Psychiatry 116: 327-333.

36. Combs D, Penn DL (2004) The role of sub-clinical paranoia on social perception and behavior. Schizophr Res 69: 93-104.

37. Combs DR, Michael CO, Penn DL (2006) Paranoia and emotion perception across the continuum. Br J Clin Psychol 45: 19-31.

38. Freeman D, Garety PA (2000) Comments on the content of persecutory delusions: Does the definition need clarification? Br J Clin Psychol 39: 407-

39. Freeman D, Garety PA, Kuipers E (2001) Persecutory delusions: developing the understanding of belief maintenance and emotional distress. Psychol Med 31: 1293-1306.

40. Freeman D, Dunn G, Garety PA, Bebbington PE, Slater M, et al. (2005) The psychology of persecutory ideation I: a questionnaire survey. J Nerv Ment Dis 193: 302-308

41. Gilbert P (2000) Varieties of Submissive behaviour as forms of socia defence: their evolution, and role in depression. In Sloman L\& Gilbert P (Edn.) Subordination and Defeat: An Evolutionary Approach to Mood Disorders and their Therapy. Lawrence Erlbaum, Mahawh 3-45.

42. Gilbert $P$, Allan S (1998) The role of defeat and entrapment (arrested flight) in depression: an exploration of an evolutio nary view. Psychol Med 28: 585-598.

43. Gilbert P, Allan S, Trent DR (1995) Involuntary subordination or dependency as key dimensions of depressive vulnerability. J Clin Psychol 51: 740-752.

44. Gilbert P, Pehl J, Allan S (1994) The phenomenology of shame and guilt: an empirical investigation. Br J Med Psychol 67: 23-36.
45. Gilbert P, Gilbert J, Irons C (2004) Life events, entrapments and arrested anger in depression. J Affect Disord 79: 149-160

46. Gilbert P, Irons C, Olsen K, Gilbert J, McEwan K (2006) Interpersonal sensitivities: their links to mood, anger and gender. Psychol Psychother 79: $37-51$

47. Goss K, Gilbert P, Allan S (1994) An exploration of Shame measures-I: "The Other as Shamer Scale". Pers Individ Dif 17: 713- 717

48. Green CE, Freeman D, Kuipers E, Bebbington P, Fowler D, et al. (2008) Measuring ideas of persecution and social reference: the Green et al. Paranoid Thought Scales (GPTS). Psychol Med 38: 101-111.

49. Horan WP, Ventura J, Nuechterlein KH, Subotnik KL, Hwang SS, et al. (2005) Stressful life events in recent-onset schizophrenia: reduced frequencies and altered subjective appraisals. Schizophr Res 75: 363-374.

50. Martin JA, Penn DL (2001) Social cognition and sub-clinical paranoid ideation Br J Clin Psychol 40: 261-265.

51. Myin-Germeys I, van Os J (2007) Stress reactivity in psychosis: evidence for an affective pathway to psychosis. Clin Psychol Rev 27: 409-424

52. Van Os J, Verdoux H (2003) Diagnosis and classification of schizophrenia categories versus dimensions, distributions versus disease. In The Epidemiology of Schizophrenia (ed. RM Murray, PB Jones, E Susser, J van Os and M Cannon), Cambridge University Press, Cambridge 364-410.

53. Spielberger CD, Jacobs GA, Russell S, Crane RS (1983) Assessment of anger: The state-trait anger scale. In: JN Butcher, CD Spielberger, eds. Advances in Personality Assessment.Lawrence Erlbaum Associates, Inc, Hillsdale, NJ 2.

54. Trower P, Gilbert $P$ (1989) New theoretical conceptions of social anxiety and social phobia. Clin Psycho Rev 9: 19-35

55. Weeks JW, Heimberg RG, Rodebaugh TL, Norton PJ (2008) Exploring the relationship between fear of positive evaluation and social anxiety. J Anxiety Disord 22: 386-400. 